\title{
The Lack of Communication and the Need of IT for Supply-Chain Management Strategies in SMEs
}

\author{
G. Fulantelli, M. Allegra, A.Z.P. Vitrano \\ Italian National Research Council, Institute for Educational Technologies \\ Palermo, Italy
}

fulantelli@itdf.pa.cnr.it allegro@itdf.pa.cnr.it avitrano@itdf.pa.cnr.it

\begin{abstract}
The term "Supply Chain Management" (SCM) denotes the creation, integration, planning and control of all elements of universal added-value chains, from the procurement of raw materials to the final delivery to the customer. IT offers huge potentials for Small and Medium-sized Enterprises to activate effective SCM mechanisms. Even though experts estimate the potential saving that can be achieved through the implementation of effective SCM strategies at 3-5 per cent of turnover, SMEs are experiencing a great deal of difficulty in coping with these strategies. Reasons for this, especially among small enterprises (50 employees and under), are to be found in the specific enterprise culture. The results presented in this paper are the outcome of an EU funded project named "Supply Chain Partnership", a pilot project aimed at analysing the communication, social and technological obstacles to the implementation of effective SCM strategies in SMEs. The focus of this paper is on the Italian experience, and concerns an industrial district located in Sicily.
\end{abstract}

Keywords: Supply-Chain Management, Information Technologies, SMEs, Communication, Cooperation.

\section{Introduction}

In literature, common definitions of Supply Chain Management are:

- The growth in economic value and its perception by the customer through the synchronized management of the raw materials and the associated information flows, from the procurement of raw materials to the consumption (B.J La Londe, Ohio State University) (Assintel, 2000);

- To have the right product in the right place, at the right price, with the right conditions ( $\mathrm{R}$. Blackwell, Ohio State University) (Assintel, 2000).

These definitions highlight the economic added-value of SCM strategies; actually, the SCM is aimed at optimising both costs and logistical volumes of productivity over all added-value chains. This optimisation extends from strategic decisions to operational implementation, and relates to all the partners involved in the added value chain.

Material published as part of these proceedings, either on-line or in print, is copyrighted by Informing Science. Permission to make digital or paper copy of part or all of these works for personal or classroom use is granted without fee provided that the copies are not made or distributed for profit or commercial advantage AND that copies 1) bear this notice in full and 2) give the full citation on the first page. It is permissible to abstract these works so long as credit is given. To copy in all other cases or to republish or to post on a server or to redistribute to lists requires specific permission from the publisher at Publisher@intormingscience.org
In effective SCM strategies, it is not enough to manage the freight movement from the supplier to the production and finally to the customer: in the supply chain all the various actions, from the procurement to the final delivery, must be synchronized and integrated using intelligent management. Integration and effective communication are therefore two key-concepts for SCM approaches. 
According to this, collaboration among the subjects along the whole chain is the first step toward the Supply chain management to have success. Managing the chain by effective strategies means, therefore, guaranteeing a continuous connection between every link of the chain through information exchange (e.g. on the stock level, on the sale trend, on the demand trend) that allows the level of Cooperation, of Communication and of Coordination (the so called "3 Cs") to increase in a meaningful way; the effect of this is to decrease the dead times and the stocks.

In order to make effective communication mechanisms along the chain, Information and Communication Technologies are considered to be the ideal solution for solving the problems related to the application of SCM strategies: IT can improve contacts all along the chain (suppliers of raw materials, other suppliers, manufactures, logistics, wholesalers, retailers and the end customers); by accelerating the communication processes, should produce competitive advantages, such as improving the capability of the company to satisfy the variations in commercial demand, increasing its innovation capabilities, boosting its competitiveness as a whole and, finally, giving a better customer service and, consequently, increasing the number of satisfied customers.

Even though experts estimate the saving potential that can be achieved through the implementation of effective SCM strategies at 3 to 5 per cent of turnover, SMEs are experiencing a great deal of difficulty in coping with this strategies.

At the Italian National Research Council, we have carried out a pilot project aimed at analysing the communication, social and technological obstacles to the implementation of effective Supply Chain Management strategies in Small and Medium-sized Enterprises. The study has been done in the framework of a European funded project named "Supply Chain Partnership" (Project funded by DG Enterprise, EC-Project-Number SUB / 00 / 502663). The project involves partners from Germany, Great Britain and Italy.

The focus of this paper is on the results from the Italian reality, and specifically on an industrial district located in Sicily that is highly representative of the companies in the southern part of Italy.

The project has shown different problems; firstly, micro-enterprises (1-9 employees) and SMEs (10-199 employees) do not have full awareness about the potentials of the new technologies, even if the project has shown a very positive trend towards better results; then, they undergo serious problems in introducing IT into their organization processes: micro-enterprises and SMEs suffer from the IT skill-shortage problems and do not have the capabilities to perform the organisational changes that are necessary to activate IT-based processes. However, amongst the others, the Cooperation in general seems to be much a more serious problem: in fact, cooperation between SMEs is not a direct consequence of an improved communication process: according to some recent economical studies on the economical development in Sicily, it has been shown that the cooperation between SMEs is extremely limited, and usually it is aimed at defining marketing consortia. Cooperation at production level is still restricted to a very small number of enterprises.

After a detailed economical analysis of the geographical regions where the clothing enterprises involved in the project are located, the authors have performed an in-depth investigation of the social, economical and technological factors which obstacles the relationships among enterprises which are required for the implementation of effective SCM strategies.

In the next section, we give an overview on the distribution of SMEs in Italy and on the use of IT, with special attention on the South Italy situation; then we present the results from the SCP project. 


\section{Italian Enterprises and Information Technology}

Most of the Italian enterprises are classifiable as SMEs (with a number of employees between 10 and 199) and micro-enterprises (with less than 10 employees); a study from one of the most important Italian statistics institute (ISTAT) estimates that SMEs are about $180.000(5,1 \%$ of the total number of enterprises) and micro-enterprises are about 3,4 million (94,8 \% of the total number of enterprises); most of them are localized in the North of Italy and only the $28,3 \%$ in the South. However, in the last years an inversion of trend has been observed: the number of entrepreneurs in the South of Italy is increasing, cutting down the gap with the rest of the country; this increment is due exclusively to SMEs and microenterprises (because the absence of big firms). We have to notice that $66 \%$ of enterprises in the South has a single employee, and that micro-enterprises constitute the $97 \%$ of all the enterprises (SMAU Ricerche, 2001).

Concerning the use of computers and Internet in SMEs, statistics report that $86,4 \%$ of firms in the South uses information technologies; among these, the $84 \%$ is connected to Internet, mainly by means of ISDN, because of its good quality/price ratio (the xDSL connections are not available in the whole country). Of course, we have to distinguish among the different uses of Internet, in relation with the size and the activity of the enterprise; in fact, while the percentage of enterprises with their own web site is about the $40,1 \%$ of computerized enterprises (Eurostat, 2002), we have to highlight that the web site is mainly used to describe the firm and the products/activities (in the $84 \%$ of the cases) and rarely it is used to manage the relationships with customers; in fact, only one on twenty sites gives also the possibility of interacting and communicating with the enterprise, and the percentage of use of Internet for the e-procurement is very low. A further interesting figure is the amount of sites including catalogues, around $45 \%$.

According to these statistics and other studies, it comes out how Internet is, up to day, not used by Italian enterprises to activate innovative processes of management, even though an in depth analysis of the above mentioned statistic shows that the awareness of IT potentialities is increasing among the SMEs entrepreneurs.

\section{The “Supply Chain Partnership" Project: the Clothing Industry in Valguarnera}

According to recent literature, the competitiveness of the Italian industrial sectors (Sicilian sectors, in particular) is founded on the local specialization of several products: the "made in Italy" is, in fact, the outcome of a particular cultural atmosphere.

Following the European "Supply Chain Partnership" project's direction, we have focused on two macro sectors: the textile and building one, and, in particular, on the Sicilian reality which presents the typical characteristics of the SMEs allocated in the South of Italy, as already mentioned in the previous section.

Throughout our study, we have therefore considered the peculiar economic and cultural condition in this industrial area of Italy; by taking into account the correlation between production competitiveness and its territorial distribution, our analysis has revealed the existence of two specialized industrial networks in two specific local areas of Sicily: Enna for clothing branch and Trapani for marble branch. In particular, in these two Sicilian areas we have identified one entrepreneurial group in Valguarnera Caropepe (Enna), which specializes in the production of men' suits, and another in the area of Trapani-Custonaci, specializing in the extraction and manufacturing of marble.

In Valguarnera there are 8 fashion firms that produce $70 \%$ of the Sicilian clothing output and export over $60 \%$ of their production. The district of Trapani-Custonaci includes about 120 small and medium-sized enterprises, even though the 30 largest companies produce around 90\% of the PIL of the area. 
We have selected an entrepreneurial sample composed of 5 firms in Valguarnera, and 9 firms in the district of Trapani-Custonaci; all present a remarkable value according entrepreneurial size, employment and economical relationships.

In particular, it is necessary to specify that three of the five sample enterprises of Valguarnera are SMEs and two enterprises are micro enterprises; in Trapani all the 9 enterprises are SMEs.

The study has been performed through workshops with the entrepreneurs and managers of the companies, and through a questionnaire aimed at analyzing the relationships between a company and their suppliers, sub-contractors, intermediaries and end customers. During the workshops, entrepreneurs and managers have been encouraged to report on their view of the added-value chain their company belong to, to identify the problems in the management of the chain and, above all, to compare their view with people responsible for other parts of the chain. The questionnaire has allowed the authors to gather precise information on the structure of the added-value chain for each company.

The results of the questionnaires and the workshops put in evidence the structural differences between the entrepreneurial reality of Valguarnera and the Trapani-Custonaci one, according the IT use to improve the communication in the Supply Chain.

In the marble industry of Trapani not only is there a remarkable lack of commercial cooperation at every phase of industrial processes, but the new information technologies are also not considered to be a strategic factor in the success of an enterprise. The web sites are only used to advertise enterprises without feedback from customers. In general, the entrepreneurs of the district in Trapani do not believe the Information Technologies can increase the communication in the Supply Chain and, consequently, the turnover by using new technological instruments (such as e-business).

Because of all these reasons, in this paper we shall focus on the entrepreneurial structure of Valguarnera, which presents a new growing awareness of the importance of IT.

\section{The Clothing Industry in Valguarnera: the Cooperation and the Communication in the Procurement Phase}

Before analysing the SCM strategies adopted by the enterprise of Valguarnera, and particularly the role of the communication in the procurement phase, it is necessary to specify that the sample enterprises have set up a consortium - whose constitution was encouraged and facilitated by the local administration - that adopts a trademark, "Tessilitalia", to guarantee that the products have been made exclusively in Italy.

Inside the consortium the sample is composed of three leading enterprise in the production of classic suits for men and two subcontractors that supply the former with the "rollino" (inside part of the jacket), the "plastron" (front part of the jacket) and inside parts of the ties.

The sample enterprises present two different levels of cooperation in the procurement phase: we can distinguish between cooperation inside the outside the consortium.

\section{The cooperation and the communication inside the consortium}

Inside the consortium there is a strong cooperation but it is restricted to exchange general information; there is not, instead, cooperation in the procurement phase: the enterprises, in fact, purchase independently different raw materials or semi finished products from different suppliers: every enterprise purchases textile that are different in quality and price to produce a product that satisfies the qualitative and economic requirements of the end customers.

However, there is a high level of communication (communication is the basic element in the relationship among enterprises), in a context in which the presence of the subcontractors is aimed at supporting the production activity of the leading enterprises of Valguarnera. 
It is necessary to specify, first of all, that the setting up of the subcontractor enterprises has been promoted by the pre-existing local enterprises to overcome to the difficulties connected to the geographical position: Valguarnera is a small town in the Sicilian hinterland, in a location, therefore, that highlights even more the isolation of Sicily in comparison to the rest of Italy. The geographical position and the isolation, therefore, is a very important element in managing the chain because all the textile suppliers are situated in the north of Italy (1500 Km from Valguarnera); then, even if there is good information exchange, the distance between enterprises and suppliers not only represents an obstacle to the management of the relationships, but it also causes an increase in the production costs and influences the management of the stocks (stocks are reduced to the minimum to save both on the costs of transport and the storage).

Because of these problems and the difficulty in being competitive in the market, the leading enterprises have encouraged the setting up of local subcontractors that are influenced by the management, the decisions and the economic progress of these enterprises (subcontractors work on commission and, therefore, if the production of the leading enterprises is greater, the orders grow).

For this reason, in the phase of the procurement, the degree of communication inside the consortium is very high; there is a good information exchange: the subcontractors receive data about the need and the requirements of the leading enterprises, the leading the enterprises receive data about the production capacity and the forecasts of production from the supplier.

The communication inside the consortium is not facilitated by the use of IT; there is a traditional communication between the leading enterprises and the subcontractors.

\section{The cooperation and the communication outside the consortium}

While inside the consortium there are strong connections between the enterprises, instead there are not any outside. Therefore, outside the consortium there is no a high degree of cooperation and communication. As already mentioned, information exchange between the leading enterprises and the suppliers is rather weak because of the geographical distances: there is one-way communication in which the enterprises of Valguarnera give information about the orders and the expectations of orders to suppliers but do not receive data about the production capacity and the forecasts of production from the suppliers.

At the moment the typical situation in the procurement phase is that represented in Figure 1. The subcontractors are free to choose their suppliers and they exchange information with them; the subcontractors then exchange this information with the leading enterprises - because the management of leading enterprises influences the internal management of subcontractors - but leading enterprises do not exchange information with subcontractors about their own suppliers.

The communication is facilitated by the use of simple IT-based solutions such as web sites (to obtain general information) and e-mail, side by side with more traditional communication tools, but not innovative technological solutions. 


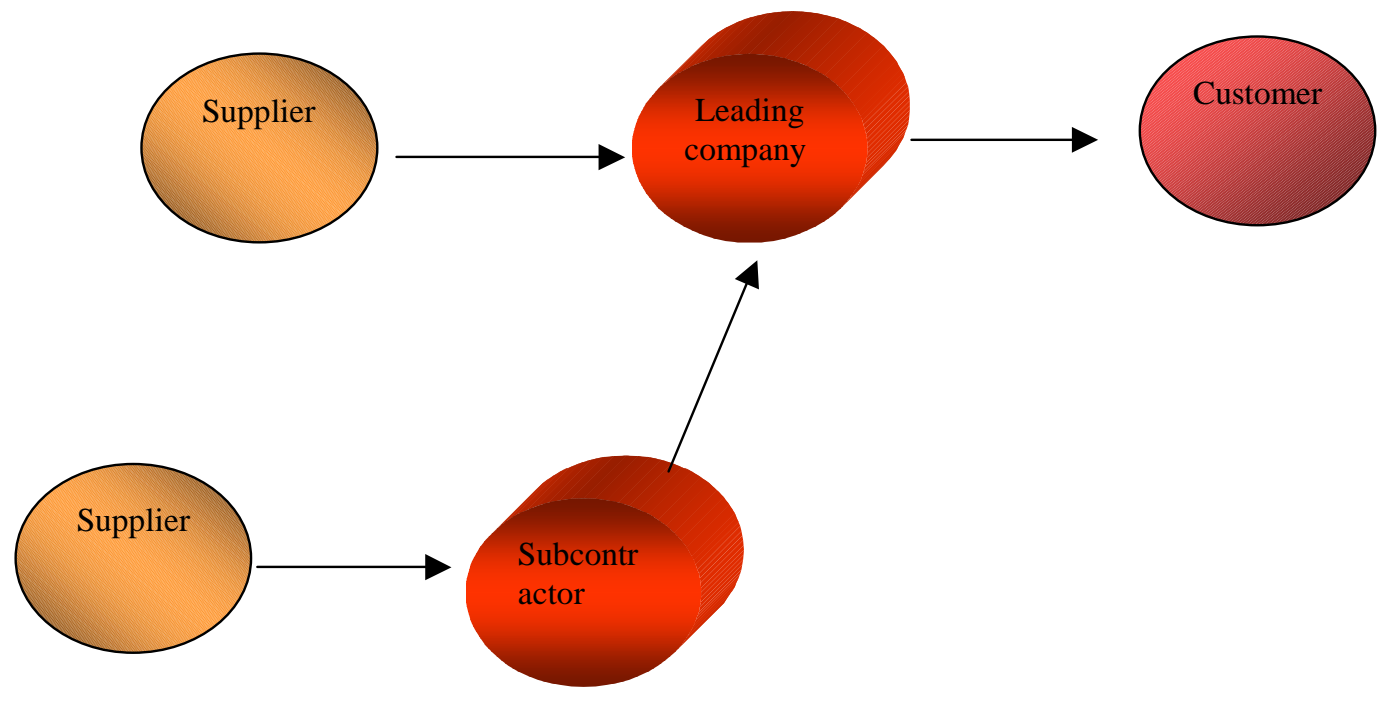

Fig. 1 -Supplier-subcontractor-leading company relationships

\section{The Clothing Industry in Valguarnera: the Cooperation and the Communication with the Sale Market}

Before analysing the degree of communication in this phase of the supply chain, it is necessary to make a brief introductory statement about the sales market of the leading enterprises of Valguarnera to understand the kind of relationships between them and their customers (we refer only to the leading enterprises because the sales market of subcontractors is influenced by that of the leading enterprises).

The sales market of these enterprises is mainly national (around 50\%); apart from minor percentages (5\% both at European and Mediterranean level and 9\% at regional level), 31\% of the products of the leading firms of Valguarnera is delivered outside the European and Mediterranean markets (Fig. 2).

At a national level relationships with the customers are mediated by the presence of trusted sale representatives in every region, who personally investigate the customer satisfaction regarding the quality and price of the products.

Interpersonal relationships are based on very traditional approaches (face-to-face meetings, phone calls, fax, and so on); e-mail is used only in few and specific circumstances to make communication process easier, but this is still a very limited use of the e-mail potentials.

In foreign markets communication requires even more using strategies and technologies to guarantee a global presence: one solution could be, for instance, the application of e-business systems whose two basic key elements should be the opening of a web-site and the planning of a specific marketing strategy.

In fact, one of the sampled enterprises - a leader in the production of ties - is introducing a policy of expansion towards international markets through the implementation of a Web site and of an e-commerce structure: the structure of electronic sales will be supported by a policy of marketing directed at uppermiddle classes of American consumers, through the mailing of a CD that will contain the description of its production system and the customer service in addition to a brief presentation of Sicily and its natural and architectural beauties to attract people's attention. 
Fulantelli, Allegra, \& Vitrano

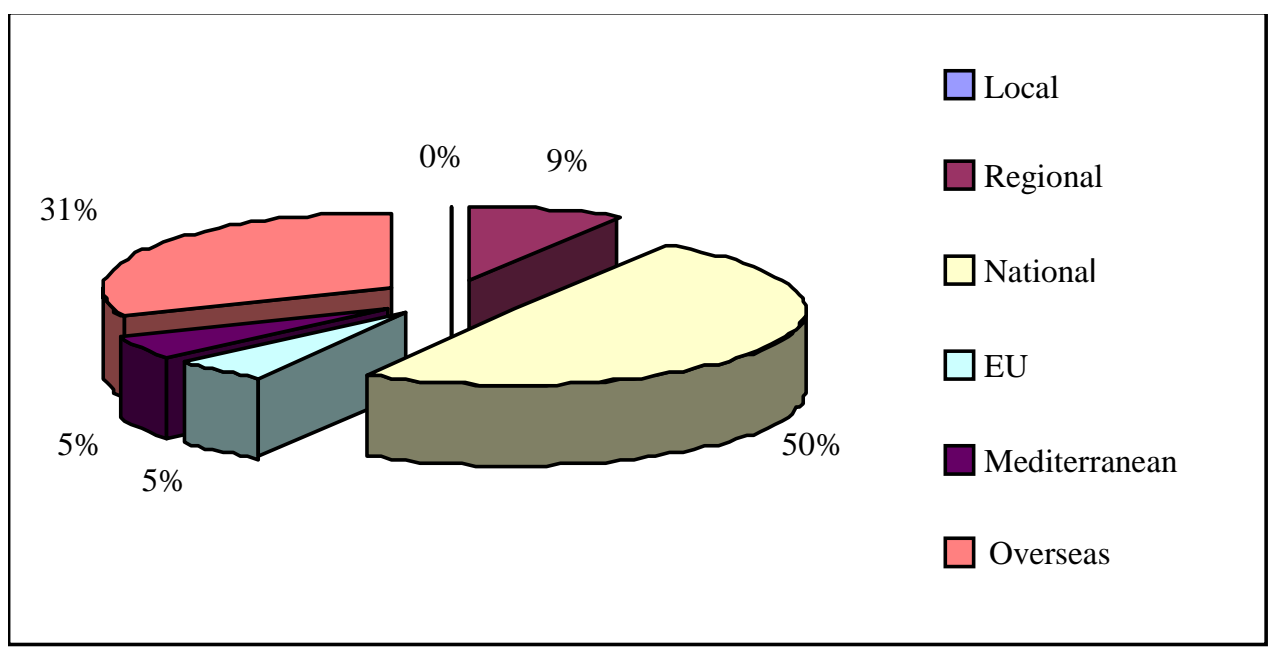

Fig. 2 - Valguarnera: sale market

It is a clear demonstration of a new awareness: the Net is seen as tool allowing enterprises to operate anywhere in the world without limits of space and time. This new awareness can open up opportunities for better management of commercial relationships, for increasing the competitiveness in a competitive environment, for guaranteeing continuity in the relationships with the customers, for personalizing the service, for facilitating orders and payments, for obtaining quick responses to the demands, and for offering information to the customer immediately whatever the distance. Even if this new awareness is increasingly widespread in the culture of the remaining enterprises in Valguarnera, they continue, however, to distrust the use of an e-commerce system with the consumers: in the fashion sector it is unlikely that the end customer will purchase suits from a catalogue or by mail-order. On-line purchases do not allow the customer to touch the clothes and therefore to feel the quality and see how the product fits. This problem is very widespread at a national level; on the basis of a study by Centro di Informazione Tessile dell'Emilia Romagna, in fact, in Italy none of the SMEs in this sector use e-business.

\section{Conclusions}

In this paper we have reported on the outcomes from a European Commission funded project named "Supply Chain Partnership", a pilot project aimed at analyzing the communication, social and technological obstacles to the implementation of effective Supply Chain Management strategies in Small and Medium-Sized enterprises.

The focus of the project has been on two industrial districts in Sicily, that are representative of the entrepreneurial situation in the southern part of Italy, even if the most significant results, illustrated in the paper, concern the clothing industry located in Valguarnera Caropepe.

The analysis carried out in the project has shown that, in the clothing industry in Valguarnera there is a strong awareness of the importance of an effective management of the supply chain; the leading SMEs of that district have activated a very good organized relationships with local suppliers, but they cannot make the same with the suppliers of the North of Italy due to the distance.

Concerning the use of IT, even though the SMEs involved in the project consider communication to be central in the management of the relationships with outside enterprises, they exchange information mainly by traditional means (i.e. fax, phone) and more rarely by means of new tools, such as e-mail, Internet, and so on. From a more in-depth analysis we noticed that this was not due to the lack of awareness about the potentials of the new technology; in fact these are used for the relationships inside the enterprise, improving the production processes and making them more effective; the leading enterprises in 
Valguarnera use information systems to manage all the phases of production, because they can check the progress of the manufacturing of each product until the final step. Entrepreneurs are aware that IT are powerful means for reducing the geographical distance between Sicily and the most industrialized part of the country and that can be extremely useful for fostering the development of SCM strategies; however, the social factors underpinning the relational and communication interfaces between SMEs are the main obstacle to the boosting of SCM strategies in Sicily: a systematic use of IT for business is a direct consequence of trustiness and cooperation between SMEs. In particular, in the industrial district that we have analysed there are several approaches to the use of IT and, of course, this is related to the different kinds of activities. In the clothing industries there is awareness that IT, and in particular B2B solutions, can improve the effectiveness of communication with suppliers improving in general the supply chain and their production. Besides, it is possible to state that there is a correlation between the experience in competitive market and the vocation to SCM strategies as well as to using IT for innovative market strategies.

Two practical advices that can be provided as a result of the research reported in this paper are to foster the knowledge of market dynamics and to guide SMEs to gain experiences in business cooperation through specific and non-ambitious projects based on common interest.

\section{References}

Assintel (2000). Internet nella comunicazione con i fornitori: la supply chain e l'e-procurement nei processi produttivi, Camera di Commercio di Milano.

Assintel (2001). Internet nella relazione con i fornitori: la supply chain nei processi produttivi, Camera di Commercio di Milano.

Baccarani C., Golinelli G.M. (1993). Tratti del divenire dei distretti industriali, in Testimonianze sull'impresa distrettuale e sull'evoluzione delle aree a specializzazione produttiva, Quaderno n. 8, Istituto Guglielmo Tagliacarte, Roma.

Becattini G. (1998). Distretti industriali e made in Italy. Le basi socio-culturali del nostro sviluppo economico. Torino: Bollati Boringhieri.

Brynjolfsson E., Hitt L.M. (2000). Beyond computation: information technology, organizational transformation and business performance, Sloan School of Management, MIT.

Cainello G., De Liso N., Perani G. (2000). Technological innovation in the service sector, Quaderno n. 11 del Dipartimento di economia, istituzioni e territorio dell'Università di Ferrara.

Calza, Passaro (1997). EDI network and logistic management at Unilever Sagit. Supply Chain Management - An International Journal, Vol. 2, N.4.

Chiarvesio M., Di Maria E., Miceli S. (2000). Distretti industriali tra rinnovamento strategico e reti tecnologiche: alcuni scenari possibili, XXI Conferenza Nazionale di Scienze Regionali, Palermo.

Dicken P., Lloyd P. (1993). Nuove prospettive su spazio e localizzazione, Milano: Franco Angeli Editore.

Eurostat (2002). Nelle PMI Italiane avanza la tecnologia. from the World Wide Web http://www.smau.it/smau

Evangelista-Velleco (1996). Management of logistic activities in SME's. Some empirical evidence in the Italian footwear industry, Fifth International Purchasing \& Supply Education \& Reaserch Association (ISPERA) Annual Conference, Eindhoven University of Technology, Eindhoven, Olanda, 1-3 Aprile

Hitt L.M. (1998). Information Technology and firm boundaries: evidence from panel data, University of Pennsylvania, The Wharton School.

Lombardi M. (1994). L'evoluzione del distretto industriale come sistema informativo: alcuni spunti di riflessione, "L'industria" n. 31, Il Mulino, Bologna.

Medugno M. (2000). B2B, B2C, One-To-One marketing, Mobile E-Commerce: analisi delle tecnologie ed evoluzione dei mercati agli albori della new economy, XXI Conferenza Nazionale di Scienze Regionali, Palermo.

Mimmo M.C. (2000). E-Marketing:uno strumento per l'evoluzione delle gerarchie d'impresa?, XXI Conferenza Nazionale di Scienze Regionali. 
Osservatorio sull'economia siciliana (1999). I sistemi locali manifatturieri in Sicilia. Analisi dei potenziali distretti industriali, Quaderno di ricerca n. 2, Banco di Sicilia.

Sacchetti S., Sugden R. (2000). La natura e l'impatto dei network industriali di subfornitura, Quaderno del Dipartimento di economia, istituzioni e territorio dell'Università di Ferrara, n. 4.

Scandizzo P.L., Atella P. (1997). Fattori di rischio e di sviluppo nelle nuove imprese del mezzogiorno. Franco Angeli ed.

Schreyer P. (2000). The contribution of information and communication technology to output growth: a study of the G7 Countries. OECD Directorate for science, technology and industry, working paper n. 2.

Smau Ricerche, (2001). Tecnologie ICT e Mezzogiorno: ruolo e opportunità di sviluppo. Smau.

Unione Camere (2001). Sistema Informativo Excelsior 2001, from the World Wide Web http://www.excelsior.unioncamere.it/

\section{Biographies}

Fulantelli Giovanni graduated in Computer Science at the University of Milan in 1990. In 1991 he won a fellowship at the Italian National research Council; his fellowship was in part funded under a grant from the SGS-Thomson Microelectronics. During the related activities, he has designed and developed multimedia technical documentation packages for microelectronic devices, that have been used to train technicians inside and outside the manufacture factory. Since 1994, he has been working as researcher at the Italian National Research Council, Institute for Educational Technologies. His research interests focus on two primary areas: multimedia-based Education and Distance Learning, from both technological and methodological points of view. He is in charge of several national and international research projects. These include the European project "Supply Chain Partnership", and the "D.A.W.N." project (Designing Architecture Working on the Net), a Web.based instruction system to support distance and cooperative learning in Architecture design.

Allegra Mario graduated in Computer Science at the University of Pisa in 1987. Since 1989 he has been a researcher at the Italian National Research Council, Institute for Educational Technologies (since 2001 he is a senior researcher); he has participated in starting up the Institute's activities, in training new personnel, in promoting and carrying out research projects concerning Information and Communication Technologies and their application in education and training contexts. His research activity has concentrated on multimedia systems and distance education technologies. He is in charge of several national and international research projects. These include the European project "SOLARE", concerning environments to support on line SMEs in Sicily, the "Virtual Classroom" project, aimed at the definition and experimenting models for network cooperation among students of junior high school, and the "L.E.M.M.A." project, Learning Environments based on Multimedia MicroActivities.

Vitrano Antonia Zelia Pia graduated in Law at the University of Palermo in July 2000; since October 2000 she has been collaborating with the Italian National Research Council, Institute for Educational Technologies. Her research activity is focused on Supply-Chain Management, e-commerce, digital signature, quality certification. She works on several national and international research projects, that include the European project "Supply Chain Partnership", concerning the communication, social and technological obstacles to the implementation of effective SCM strategies in Small and Medium-sized Enterprises. 